\title{
The most common preanalytic problem of sweat testing: Insufficient sweat volume
}

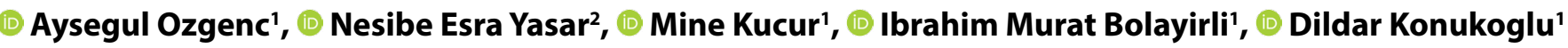

'Department of Medical Biochemistry, Cerrahpasa Faculty of Medicine, Istanbul University-Cerrahpasa, Istanbul, Turkey

${ }^{2}$ Republic of Turkey, Ministry of Health Kars Harakani Public Hospital, Kars, Turkey

\begin{abstract}
Objectives: A sweat test is the gold standard method for the diagnosis of cystic fibrosis (CF). The most important preanalytical error for sweat testing is insufficient sweat volume. The aim of this study was to determine rates of insufficient sweat volume and evaluate the relationship of sweat volume with demographic characteristics of patients, as well as the implementation of corrective preventive actions.

Methods: This study was performed retrospectively in the sweat test laboratory of the Cerrahpasa Faculty of Medicine of Istanbul University-Cerrahpasa. A total of 545 specimens that were referred to the laboratory between May and December 2016 were evaluated. Sweating was stimulated with pilocarpine iontophoresis, and the Macroduct Coil System (Wescor, Inc., Logan, UT, USA) was used as the sweat collection system. Sweat volume $<15 \mu \mathrm{L}$ was evaluated as quantity not sufficient (QNS). A chi-square test was used for statistical analysis; $\mathrm{p}<0.05$ was considered significant.

Results: The QNS rate in the study laboratory was $13.8 \%$ for infants $\leq 3$ months of age and $6 \%$ for patients aged $>3$ months $(p=0.019)$. There was no significant difference in the QNS ratios according to gender $(p=1.000)$ or the season when the test was applied $(p=0.181)$.

Conclusion: The determination of QNS rates is a crucial step in the standardization of the preanalytical conditions of a sweat test. In this study, the QNS rate was above that recommended by the Cystic Fibrosis Foundation $(<10 \%$ for infants $\leq 3$ months of age, $<5 \%$ for patients $>3$ months). High QNS ratios may be due to the inadequacy of optimization of pre-test preparation. Laboratory staff and parents should be well informed about preanalytical factors before a sweat analysis is performed in order to reduce the QNS rate.
\end{abstract}

Keywords: Cystic fibrosis, preanalytical phase, quantity not sufficient, sweat collection

C ystic fibrosis (CF) is a fatal disease, an inherited autosomal recessive disorder resulting from mutations in the CF transmembrane conductance regulator gene, located in the long arm of chromosome 7 [1]. The prevalence is about 1 in 3500 live births [2]. According to the limited number of studies, the incidence of $\mathrm{CF}$ is about 1/3000 in Turkey. However, the rate is thought to be higher due to the frequency of consanguineous marriage [3]. In studies, early diagnosis and treatment has led to improved nutritional status and lung function, prolonging the life span by reducing hospitalizations and morbidity $[1,4]$.
Therefore, CF has been part of newborn screening programs in some parts of the world for many years [5]. In Turkey, all newborns have been screened for immunoreactive trypsinogen from a dried blood spot since January 1, 2015 and positive cases are referred for a sweat test.

The sweat test is the gold standard method for the diagnosis of CF based on the quantitative determination of electrolytes in the sweat sample [6]. The test consists of 3 steps: Stimulation of sweat glands by pilocarpine iontophoresis, sweat collection, and analysis. The primary sweat collection methods

Address for correspondence: Aysegul Ozgenc, MD. Department of Medical Biochemistry, Cerrahpasa Faculty of Medicine, Istanbul University-Cerrahpasa, Istanbul, Turkey

Phone: +90 2124143000 (61797) E-mail: aysegulozgenc.dr@gmail.com ORCID: 0000-0001-8833-1389

Submitted Date: December 21, 2019 Accepted Date: March 05, 2020 Available Online Date: April 20, 2020

${ }^{\circ}$ Copyright 2020 by International Journal of Medical Biochemistry - Available online at www.internationalbiochemistry.com

OPEN ACCESS This work is licensed under a Creative Commons Attribution-NonCommercial 4.0 International License. 
are the Gibson-Cooke procedure and use of the Macroduct sweat collection system (Wescor, Inc., Logan, UT, USA). In both of these systems, after stimulation of sweating, gauze, filter paper, or a collector is used to collect the sweat sample [7].

The preanalytical phase is defined as processes that start, in chronological order, from the clinician's request and include the preparation and identification of the patient, collection of the primary sample(s), and transportation to and within the laboratory, and end when the analytical examination begins [8]. Preanalytical mistakes account for up to $70 \%$ of all errors made in laboratory diagnostics, most of which arise from problems in patient preparation, sample collection, transportation, preparation for analysis, and storage [9]. The most important preanalytical error encountered during sweat testing is insufficient sweat volume. Factors that influence sweat volume include age, sex, body weight, race, condition of the skin, and the collection system used [10]. The minimal acceptable sweat volume for analysis is $75 \mathrm{mg}$ for the Gibson-Cooke procedure and $15 \mu \mathrm{L}$ for the Macroduct system $[7,11]$. Lower weights or volumes of sweat specimens cannot be analyzed and are labeled as quantity not sufficient (QNS) [2]. The aim of this study was to evaluate the data of 1 sweat test laboratory to determine the rate of insufficient sweat volume and the eventual implementation of corrective preventive actions.

\section{Materials and Methods}

\section{Study population}

This study was performed retrospectively in the sweat test laboratory of the Cerrahpasa Faculty of Medicine of Istanbul University-Cerrahpasa. In addition to infants with positive newborn screening (immunoreactive trypsinogen) for CF, children and adults are also referred to the study sweat test laboratory.

\section{Processing and data storage}

A total of 545 specimens that were referred to the laboratory between May and December 2016 were evaluated retrospectively, of which 59 were newborns with positive screening results. Details of the adequacy of sweat volume (sufficient/ insufficient), sex, the date of birth, the date the sweat test was performed, and which service requested the test, were obtained from the laboratory information system. The patient's age at the time of the sweat test application was calculated according to the patient's date of birth and the date of the application of the test. QNS ratios were calculated as the proportion of tests reported as inadequate sweat volume to the total number of sweat tests. QNS rates were calculated for patients aged $\leq 3$ months and $>3$ months of age. The adequacy of sweat volume was also evaluated for patients $\leq 3$ months of age based on the number of weeks of life. In addition, QNS rates were examined according to gender and the season in which the test was performed. Tests applied in summer (MayAugust) and winter (September-December) were analyzed and QNS ratios were calculated according to the season.

\section{Test method}

As a pre-test protocol, written information was given to the patients before the test, and the families of patients provided oral responses about factors that might have the possibility of affecting sweating volume using the following guidelines:

1. Fluid intake in the days prior to the test is important. Pay attention to consumption. Liquids such as water, hot milk, or breast milk should be consumed at least 1 hour before and during the application of the test.

2. The patient should be bathed 24 hours before the appointment date; however, no cream, baby body oil, lotion, etc. should be applied to the arms and legs.

3. Try to avoid conditions in which the patient might sweat before the test.

4. Warming materials, such as blankets, should be provided if it is required for optimum sweat volume.

5. A sweat test should not be applied to patients who have limited hydration.

The test was performed by certified technical personnel and medical biochemistry specialists. The front of the forearm or leg was the preferred application site for infants. A Wescor Macroduct coil system was used as the sweat collection system. The iontophoretically-stimulated area on the skin was cleaned with alcohol and deionized water, and 2 electrodes with $2.8 \mathrm{~cm}$-diameter solid agar gel discs (CF $\Delta$ discs, UCF 100) containing $0.5 \%$ pilocarpine nitrate in $96 \%$ water were placed on the forearm. The electrodes (UCF 2010 Iontophoresis Unit; UTSAT Sağlık Teknolojileri San. Tic. Ltd., Istanbul, Turkey) were supplied with a maximum of $1.5 \mathrm{~mA}$ current for 5 minutes. After the stimulation, the electrodes were removed and the skin was cleaned with deionized water and thoroughly dried. Subsequently, the collector (UTS021 CF $\triangle$ Collector; UTSAT Health Technologies Industries, Ltd., Istanbul, Turkey) was placed on the area where the positive electrode was located, sealed with film to prevent evaporation, and left for 25 minutes to obtain adequate sweat volume. A sweat volume $<15 \mu \mathrm{L}$ ( $<3$ spiral) was evaluated as inadequate.

The Macroduct collector that was used in this study is a disposable, concave plastic disc and a spiral plastic tube with an inner diameter of $0.64 \mathrm{~mm}$ and a total capacity of about $85 \mu \mathrm{L}$, with a 0.025 -inch hole in the middle of the disc. The sweat sample accumulates in the plastic tube and transitions through the hole, avoiding the risks of dead space or evaporation. A blue, water-based paint on the underneath surface of the concave disc that does not interfere with the electrolytes in the sample allows for the clear visualization of the sweat inside the plastic collection spiral. The quantity of sweat that could be obtained during the test was recorded.

After collection of the sweat sample, the UCF 2011 Sweat Analysis Unit (UTSAT, Health Technologies Industries, Ltd., Istanbul, Turkey) was used to determine the conductivity and the chloride concentration of sweat using the coulometric method. 
This study was approved by the ethics committee of Cerrahpasa Faculty of Medicine, Istanbul University-Cerrahpasa on May 10, 2018 (no: 171792).

\section{Statistical analysis}

Descriptive statistics were calculated using the median and range for continuous variables and the percentage for categorical variables. The Yates continuity correction was used to evaluate the difference in the QNS rate between gender, the season when the test was performed, and age ( $\leq 3$ months and $>3$ months). The difference in QNS rates in infants aged between $\leq 2$ weeks and $>2$ weeks was examined with Fisher's exact test. All of the analyses were performed using IBM SPSS Statistics for Windows, Version 20.0 (IBM Corp., Armonk, NY, USA) and $p<0.05$ was considered significant.

\section{Results}

The inpatient and outpatient services of the study hospital that most frequently requested a sweat test are provided in Figure 1.

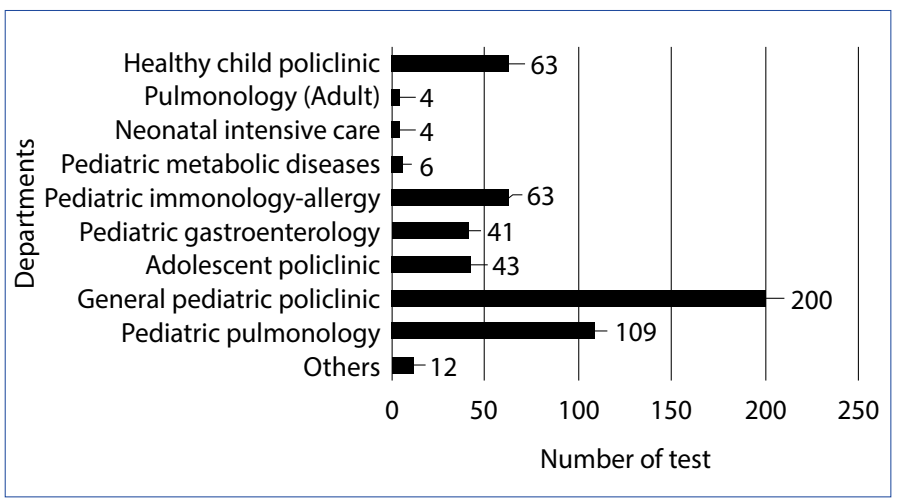

Figure 1. Distribution of the sweat test order count from inpatient and outpatient services for 8 months (May-Dec 2016).
The age of the patients ranged from 8 days to 35 years. The median age at the time of the test was 3.7 years.

A newborn screening test was positive in $10.8 \%$ of the patients and they were referred for a sweat test to confirm the diagnosis. The median age of these patients at the time the test was administered was 2.4 months.

The distribution of the patients according to sweat volume, age, gender, and season is summarized in Table 1.

In all, 40 samples had a QNS error and the sweat tests were not analyzed. The inadequate sweat volume rate in the laboratory was $13.8 \%$ for infants $\leq 3$ months of age, and $6 \%$ for patients $>3$ months of age, with a significant difference between these 2 groups $(p=0.019)$. The percentage of sweat tests that were reported as QNS according to weeks of life is shown in Figure 2. A few tests $(n=5)$ were performed within 2 weeks after birth. There was no significant difference in the QNS rate between those aged 2 weeks or less and those older than 2 weeks ( $p=0.533$ ).

Of the samples that were reported as QNS, 22 patients were male and 18 were female. When the QNS samples were com-

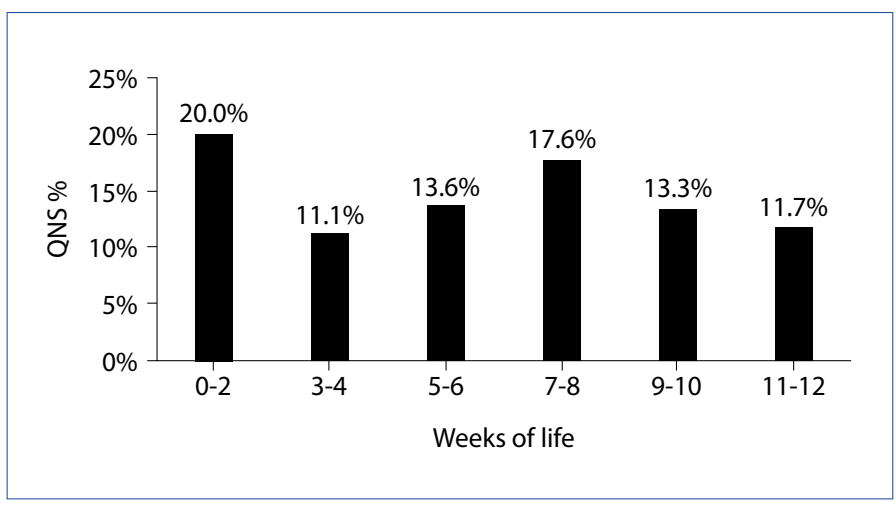

Figure 2. Percent of sweat tests reported as quantity not sufficient (QNS) at 2-week age intervals.

Table 1. The distribution of the patients according to sweat volume, age, gender, and season

\begin{tabular}{|c|c|c|c|c|c|c|c|}
\hline & \multicolumn{6}{|c|}{ Sweat volume } & \multirow[b]{3}{*}{$\mathbf{p}$} \\
\hline & \multicolumn{2}{|c|}{ Overall } & \multicolumn{2}{|c|}{ QNS } & \multicolumn{2}{|c|}{ Sufficient } & \\
\hline & $\mathbf{n}$ & $\%$ & $\mathbf{n}$ & $\%$ & $\mathbf{n}$ & $\%$ & \\
\hline \multicolumn{8}{|l|}{ Age } \\
\hline$\leq 3$ months & 94 & 17.2 & 13 & 13.8 & 81 & 86.2 & 0.019 \\
\hline$>3$ months & 451 & 82.8 & 27 & 6 & 424 & 94 & \\
\hline \multicolumn{8}{|l|}{ Gender } \\
\hline Female & 242 & 44.4 & 18 & 7.4 & 224 & 92.5 & 1.000 \\
\hline Male & 303 & 55.6 & 22 & 7.2 & 281 & 92.7 & \\
\hline \multicolumn{8}{|l|}{ Season } \\
\hline Summer & 225 & 41.3 & 12 & 5.3 & 223 & 94.7 & 0.181 \\
\hline Winter & 320 & 58.7 & 28 & 8.7 & 292 & 91.3 & \\
\hline
\end{tabular}

P value of $<0.05$ was considered significant; QNS: Quantity not sufficient. 
pared according to the season, 12 samples were observed in summer and 28 samples in winter. There was no significant difference in the QNS ratio according to gender $(p=1.000)$ or the season when the test was performed $(p=0.181)$ (Table 1$)$.

\section{Discussion}

The most important preanalytical error in sweat testing is insufficient sweat volume. A test analysis that is not evaluated due to insufficient sample volume can only be reliably repeated 2 weeks later, which leads to a delay in diagnosis, increased re-testing costs, and additional stress for both the children and their parents. Therefore, the Cystic Fibrosis Foundation (CFF) recommended that the laboratory QNS rate should be measured at certain intervals and minimized. Based on the recommendation of CFF, the standard is that QNS rates should not exceed $10 \%$ for infants aged 3 months or less and $5 \%$ for patients older than 3 months $[2,12]$. However, there is no recommendation how to reduce the rate of inadequate sweat volume in the CFF guidelines. The QNS rate of the study laboratory was above the CFF recommended rate. Especially in infants aged $\leq 3$ months, a higher QNS ratio may be explained by the fact that the pre-test preparation is more difficult. One of the precautions that can be taken to reduce the QNS rate is that a sweat analysis test should not be administered within the first 2 weeks after birth [13]. The highest QNS rate in our study was seen newborns within the first 2 weeks after birth, as has been described in the literature. It was found that there was no significant difference between the first 2 weeks and later age groups, probably due to the small number of sweat analyses performed in the newborn period. In our study, the QNS rate was similar in the age groups of 3-4, 5-6, 9-10, and 11-12 weeks, but the 7-8 weeks group had a higher QNS rate. We could not explain this elevation. Parad et al. [14] evaluated age-related differences according to inadequate sweat samples and found that the QNS rate was $17 \%$ in the first 2 weeks of life but was reduced to 3-11\% at 3-8 weeks of life.

Factors that influence sweat volume include sex, body weight, race, condition of the skin, collection systems used in analysis and age at the time of the sweat test application [10]. Collins et al. [15] reported that race and gender were not associated with QNS rates. They also showed that history of prematurity and weight of less than $3 \mathrm{~kg}$ were related to an increased chance of QNS collection. However, in this study subjects older than 3 months were not evaluated for QNS. In our study, it was found that gender had no effect on the ratio of QNS. In addition to factors previously mentioned in the literature, we found that the season when the test was performed had no effect on the sweat volume. We did not find any published study examining the relationship between sweat volume and the season when the test was administered.

In order to ensure adequate sweating, especially in outpatients, adequate hydration and skin condition are very important. The sweat analysis should be delayed in the presence of additional diseases and treatments such as corticosteroids that might affect the patient's hydration status [7]. Laguna et al. (16) recommended that hydration of at least $120 \mathrm{~mL} / \mathrm{kg} /$ day for 24 hours prior to the test and no eczema in the region of the test were essential to collect adequate sweat. In our laboratory, parents are informed about adequate fluid intake, as well as skin integrity and preparation before the analysis.

Another factor affecting the QNS rate is the sweat collection system. Standardized methods should be used both for the stimulation of sweating and the collection of the sample [13]. The risk of evaporation in Macroduct collectors is very low. Laguna et al. [16] found that the QNS rate was 2.1\% for the Macroduct method, while it was $15.4 \%$ for the Gibson-Cooke method. The precautions we applied during the preanalytic period such as tightening the collector, using Parafilm (Bemis Company, Inc., Neenah, WI, US) to avoid evaporation, and heating the room where the test is performed, may increase the sweat volume. Aqil et al. [17] developed a quality improvement program for sweat test analysis, which includes some precautions to reduce the number of QNS results when using the Macroduct method. First of all, the analysis was not performed in such conditions as a body weight $<2 \mathrm{~kg}$, a gestational age $<36$ weeks (premature), and in the first 48 hours after birth. Secondly, they noted the importance of informing the families about hydration and advising clinicians about deferment of testing for patients on intravenous infusions in the arm and patients on certain mineralocorticoids. The thigh was eliminated as a collection site. In addition they added the use of a heel warmer, and Parafilm with firm placement of the collector prevent evaporation. The number of collectors was restricted to a total of 5 . Staff training was conducted and weekly meetings were held to evaluate the QNS ratios and minimize this preanalytic problem. After these changes were implemented, the QNS rate decreased from $16.7 \%$ to $8.5 \%$ in infants aged $\leq 3$ months and from $9.3 \%$ to $2.2 \%$ in patients older than 3 months.

The staff plays a major role in the preanalytical phase of the sweat test. Therefore, limiting the number of staff who perform the test and additional staff training can affect QNS rates. In our laboratory, the test is performed by 6 laboratory technicians who have been appropriately certificated.

Obtaining sufficient sweat volume for chloride determination is very important for the early diagnosis of CF and rapid initiation of treatment. The high QNS ratios in our laboratory may be due to inadequacy of optimization of the pre-test preparation stage rather than the demographic characteristics of the patients. The determination of QNS rates is a crucial step in the standardization of the preanalytical conditions of the sweat test. After this study, we aim to ensure continuity in staff training and to evaluate the QNS rates more frequently (every month). We are also planning more effective methods to inform families about hydration, especially in young infants.

This study has some limitations, such as the short-term and retrospective study design, and the small sample size. Large, prospective cohort studies can provide more information about factors that influence sweat volume. 


\section{Conclusion}

Laboratory staff and parents should be well informed about preanalytical factors, especially hydration and skin condition before a sweat analysis in order to help reduce the QNS rate.

Acknowledgments: The authors wish to thank all of the laboratory technicians and staff who took part in the study and performed the collection and analysis of sweat tests in the participating sweat test laboratory.

This study was presented at the Association of Clinical Biochemistry Specialists Pediatric Preanalytical Symposium, Ankara, Turkey, April 21, 2017.

Conflict of interest: No conflict of interest is declared by the authors.

Ethics Committee Approval: This study received approval from the ethics committee of Cerrahpasa Faculty of Medicine, Istanbul University-Cerrahpasa on May 10, 2018 (no: 171792).

Financial Disclosure: This research did not receive any specific grant from funding agencies in the public, commercial, or not-forprofit sectors.

Peer-review: Externally peer-reviewed.

Authorship contributions: Concept - A.O., N.E.Y., D.K.; Design A.O., N.E.Y., M.K.; Supervision - M.K., I.M.B.; Funding - A.O., N.E.Y.; Materials - A.O., N.E.Y.; Data collection \&/or processing - A.O., N.E.Y.; Analysis and/or interpretation - A.O., N.E.Y., M.K., I.M.B., D.K.; Literature search - A.O., N.E.Y.; Writing - A.O., N.E.Y., M.K., I.M.B.; Critical review - M.K., I.M.B., D.K.

\section{References}

1. Domingos MT, Magdalena NI, Cat MN, Watanabe AM, Rosário Filho NA. Sweat conductivity and coulometric quantitative test in neonatal cystic fibrosis screening. J Pediatr (Rio J) 2015;91(6):590-5. [CrossRef]

2. Abdulhamid I, Kleyn M, Langbo C, Gregoire-Bottex M, Schuen J, Shanmugasundaram K, et al. Improving the Rate of Sufficient Sweat Collected in Infants Referred for Sweat Testing in Michigan. Glob Pediatr Health 2014;1:2333794X14553625.

3. Republic of Turkey, The Ministry of Health, Public Health Agency, Control program for hereditary metabolic diseases 2018-2021. Available at: https://hsgm.saglik.gov.tr/ depo/birimler/saglikli-beslenme-hareketli-hayat-db/Colyak/ Taslaklar/Kalitsal-Metabolizma-Hastaliklari-Kontrol-Programi-8-11-2017.pdf. Accessed Apr 7, 2020.
4. Beauchamp M, Grey V, Lands LC. Sweat collection for testing in Canadian Cystic Fibrosis Centers, is it optimal?. Clin Biochem 2005;38(10):934-7. [CrossRef]

5. Davies JC, Alton EW, Bush A. Cystic fibrosis. BMJ 2007;335(7632):1255-9. [CrossRef]

6. Castellani C, Southern KW, Brownlee K, Dankert Roelse J, Duff A, Farrell $M$, et al. European best practice guidelines for cystic fibrosis neonatal screening. J Cyst Fibros 2009;8(3):153-73.

7. AACB Sweat Testing Working Party, Coakley J, Scott S, Doery J, Greaves R, Talsma P, et al. Australian guidelines for the performance of the sweat test for the diagnosis of cystic fibrosis: report from the AACB Sweat Testing Working Party. Clin Biochem Rev 2006;27(2):S1-7.

8. Dikmen ZG, Pinar A, Akbiyik F. Specimen rejection in laboratory medicine: Necessary for patient safety?. Biochem Med (Zagreb) 2015;25(3):377-85. [CrossRef]

9. Plebani M, Sciacovelli L, Aita A, Padoan A, Chiozza ML. Quality indicators to detect pre-analytical errors in laboratory testing. Clin Chim Acta 2014;432:44-8. [CrossRef]

10. Farrell PM, Rosenstein BJ, White TB, Accurso FJ, Castellani $C$, Cutting GR, et al. Guidelines for diagnosis of cystic fibrosis in newborns through older adults: Cystic Fibrosis Foundation consensus report. J Pediatr 2008;153(2):S4-S14. [CrossRef]

11. Dalcin Pde T, Abreu E Silva FA. Cystic fibrosis in adults: diagnostic and therapeutic aspects. J Bras Pneumol 2008;34(2):107-17.

12. LeGrys VA, Yankaskas JR, Quittell LM, Marshall BC, Mogayzel PJ Jr; Cystic Fibrosis Foundation. Diagnostic sweat testing: the Cystic Fibrosis Foundation guidelines. J Pediatr 2007;151(1):85-9. [CrossRef]

13. Baumer JH. Evidence based guidelines for the performance of the sweat test for the investigation of cystic fibrosis in the UK. Arch Dis Child 2003;88(12):1126-7. [CrossRef]

14. Parad RB, Comeau AM, Dorkin HL, Dovey M, Gerstle R, Martin T, et al. Sweat testing infants detected by cystic fibrosis newborn screening. J Pediatr 2005;147(3 Suppl):S69-72. [CrossRef]

15. Collins MN, Brawley CB, McCracken CE, Shankar PR, Schechter $M S$, Rogers BB. Risk factors for quantity not sufficient sweat collection in infants 3 months or younger. Am J Clin Pathol 2014;142(1):72-5. [CrossRef]

16. Laguna TA, Lin N, Wang Q, Holme B, McNamara J, Regelmann WE. Comparison of quantitative sweat chloride methods after positive newborn screen for cystic fibrosis. Pediatr Pulmonol 2012;47(8):736-42. [CrossRef]

17. Aqil B, West A, Dowlin M, Tam E, Nordstrom C, Buffone G, et al. Implementation of a quality improvement program to improve sweat test performance in a pediatric hospital. Arch Pathol Lab Med 2014;138(7):920-2. [CrossRef] 